\title{
Essential List of Medicinal Products for Rare Diseases - Recommendations from the IRDiRC Rare Disease Treatment Access Working Group
}

\section{William A. Gahl}

NIH: National Institutes of Health

\section{Durhane Wong-Rieger}

Canadian Organization for Rare Disorders

\section{Virginie Hivert}

EURORDIS-Rare Diseases Europe

\section{Rachel Yang}

China Alliance for Rare Diseases

\section{Galliano Zanello ( $\boldsymbol{Q}$ galliano.zanello@inserm.fr )}

Institut national de la santé et de la recherche médicale: INSERM https://orcid.org/0000-0001-85124384

\section{Stephen Groft}

$\mathrm{NIH}$ : National Institutes of Health

\section{Research Article}

Keywords: rare disease medicine, medicine access

Posted Date: March 22nd, 2021

DOl: https://doi.org/10.21203/rs.3.rs-281700/v1

License: (c) (i) This work is licensed under a Creative Commons Attribution 4.0 International License.

Read Full License

Version of Record: A version of this preprint was published at Orphanet Journal of Rare Diseases on July 13th, 2021. See the published version at https://doi.org/10.1186/s13023-021-01923-0. 


\section{Abstract \\ Background}

Treatments are often unavailable for rare disease patients, especially in low-and-middle-income countries. Reasons for this include lack of financial support for therapies and onerous regulatory requirements for approval of drugs. Other barriers include lack of reimbursement, administrative infrastructure, and knowledge about diagnosis and drug treatment options. The International Rare Diseases Research Consortium set up the Rare Disease Treatment Access Working Group with the first objective to develop an essential list of medicinal products for rare diseases.

\section{Results}

The Working Group extracted 215 drugs with Orphan designation in the FDA, EMA databases and/or China's Rare Diseases Catalog. The drugs were organized in seven disease categories: metabolic, neurologic, hematologic, anti-inflammatory, endocrine, pulmonary, and immunologic, plus a miscellaneous category.

\section{Conclusions}

The proposed list of essential medicinal products for rare diseases is intended to initiate discussion and collaboration among patient advocacy groups, health care providers, industry and government agencies to enhance access to appropriate medicines for all rare disease patients throughout the world.

\section{Introduction}

A significant unmet need for individuals living with rare diseases is access to beneficial therapies, even those that are approved by major regulatory bodies and are considered as standards of care by experts throughout the world. This issue is especially apparent in low-and-middle-income countries (LMICs) but also affects a substantial proportion of eligible patients in high-income jurisdictions. Of course, this inequity in access applies not only to rare disease drugs but also therapies for common, chronic diseases. However, the disparity is even greater for rare disease treatments. Moreover, while there are international initiatives and programs to make available therapies for conditions affecting large patient populations, such as diabetes, HIV and cancer, there has been little action to improve access to drugs for those suffering from rare conditions.

To stimulate a broad response to this unmet need, the International Rare Diseases Research Consortium (IRDiRC) established the Rare Disease Treatment Access Working Group (RDTAWG) with three aims: 1) To improve standards of care for RD patients by promoting access to approved medicines; 2 ) To initiate 
research into the barriers to accessing RD drugs, especially in LMICs; and 3) To define opportunities to address those barriers.

This paper is the first of a three-part series with special focus on lack of access to orphan and rare disease drugs in LMICs and also inequitable access in high-income countries. This first paper presents a curated list of medicines considered to be essential for rare disorders. The second paper will discuss the barriers to access stratified by types of therapy, characteristics of rare disease populations, and key country parameters such as investment in health, health system capabilities, and rare disease priorities. That paper will also review some existing mechanisms for providing therapeutic access for rare and nonrare conditions. The third paper will consider strategies for improving access directed toward barriers identified along the patient pathway, in general and specific to rare conditions.

\section{Methods}

The IRDiRC RDTAWG developed a list of essential medicinal products for rare conditions; the list was not intended to include all medicines used to treat rare diseases but those that could be considered as essential based on approvals by key regulatory agencies in the USA, the European Union (EU) and China for the treatment of rare conditions. Two approaches were used to compile the list. The first approach was to start with databases of medicinal products with designated orphan status and/or marketing authorizations for rare disease indications. The initial references were the USA FDA Orphan Drug Product Designation database for products approved in the USA [1], the Orphanet list of Orphan Medicinal Products (OMPs) in Europe (2020) [2], and the EMA database of approved products and designations [3]. All drugs with orphan designations and FDA approval were extracted and a list arranged by generic (medicinal) name, rare condition usage and regulatory approval status was created. Medicinal products for rare diseases that have European Community marketing authorizations were then collated by using the Orphanet and EMA databases. To round out the list, China's recently published Rare Diseases Catalog $[4,5]$ of 121 rare diseases was consulted to develop a list of medicines that were approved for the treatment of recognized rare conditions.

The second approach to developing the essential rare disease medicines list was to start with the World Health Organization Model List of Essential Medicines - 21st list, 2019 [6] and the WHO Model List of Essential Medicines for Children - 7th list, 2019 [7] to extract all essential medicines that were indicated for the treatment of rare diseases. This exercise identified medicines on the FDA, EU, and/or China lists that were also on the WHO essential medicines lists; however, the WHO indication was often not for a rare disease but a more common condition. Some key exceptions are medicines for treating hemophilia, cystic fibrosis, Marfan syndrome, Prader-Willi syndrome, myasthenia gravis, and sickle cell disease. It is important to note that this list does not include any rare cancer drugs. Given the large number and the uniqueness, rare cancers deserve a separate list.

The list of medicinal products was collated by eliminating duplicates and combining medicines that were ostensibly versions of a single drug therapy. The RDTAWG identified as an initial goal the creation of a list 
of RD medicines that, based on orphan designation and approval or marketing authorization, were efficacious, safe and having a significant impact on the quality and/or duration of life. In some cases, they could be considered standards of care based on widespread and long-term use; however, no attempt was made to categorize the drugs according to life-saving, curative, or beneficial properties. Moreover, while it was desirable that the medicines on the list could be managed across a variety of countries at different stages of health system development, there was no detailed assessment on the basis of costeffectiveness, complexity of management, or requirements for administration. Hence, unlike the WHO list of essential medicines, this list of RD drugs is not stratified nor prioritized on the basis of various criteria that could affect feasibility of adoption.

This list is intended to be the initial iteration of a "living document", to be revised and updated periodically. The list is not based on definitive criteria for inclusion nor is it the product of an expert consensus process. It is not intended to be comprehensive but is proposed to the rare disease community for consideration and uptake as well as a starting point or guide for jurisdictions to set policies on provision of rare disease medicines to their populations.

The members of the RDTAWG reviewed those medications within their area(s) of expertise and, specifically, to eliminate duplicate or redundant medicines, remove drugs considered inappropriate or ineffective, add other drugs that should be on the list, and provide comments as appropriate.

\section{Results}

The Table 1 presents the current working list of essential rare disease medicines with different versions of a medication listed separately where appropriate. The list is organized into seven disease categories: metabolic, neurologic, hematologic, anti-inflammatory, endocrine, pulmonary, and immunologic, plus a miscellaneous category. Within each category, drugs are listed by subgroupings and specific conditions, with multiple indications where appropriate. The drugs are not coded in terms of priority, therapeutic strength or equivalence, need for specialized diagnosis or care, or any restrictions (cf. WHO Model List of Essential Medicines). The greatest number of drugs is in the metabolic disease category, but various neurological diseases are extensively represented.

\section{Discussion}

Individuals with rare diseases encounter many challenges along the path to appropriate care and treatment. The first obstacle for many is obtaining an accurate diagnosis, which often takes more than five years [8]. For many, the next hurdle involves finding expert care and treatment, which can vary depending upon many factors including geographic location and socioeconomic status. In fact, researchers have noted profound disparities across the globe in access to rare disease medicines, with significant impact on health outcomes and quality of life [9-11]. In 2006, Stolk et al. [12] called for inclusion of RD drugs as essential medicines, but this has not occurred. 
Many of the drugs in our RD drug list are not included in the WHO Essential Medicines List. Moreover, not all of the drugs on our list are approved across all jurisdictions, and a few with regulatory approval and/or marketing authorization are not indicated for the specified rare disease(s), even if they are recognized as appropriate or a standard of care. Based upon such a lack of indication, some health systems may choose to deny reimbursement even if the drug is inexpensive, genericized and in distribution. This problem affects patients in high-income as well as low-and-middle income countries. Therefore, it is important to take a broader contextual approach to understand the challenges rare disease patients are facing and address them collectively and systematically.

Approximately one-third of all persons worldwide, including those in low-income but increasingly middleincome countries, do not have access to essential medicines, specifically drugs, vaccines, and diagnostics for communicable, noncommunicable, social-behavioral illnesses, and emerging environmentally induced diseases [13]. The cause of the problem, like the cause of the diseases, is multifactorial and requires not only multidisciplinary and multisectoral approaches but integrated, holistic innovative solutions. Barriers at the individual level include the lack of health literacy, awareness of therapies, and advocacy capacity. Healthcare professionals similarly may lack awareness of appropriate medicines, knowledge to use effectively, and capacity to advocate for access. Major impediments at the systems level include lack of low-cost alternatives (generics and biosimilars) as well as the lack of regulatory, clinical and infrastructure capacity to make complex innovative therapies available and to deliver them to patients [14]. In addition, while nations are criticized for limited national commitment to healthcare and insufficient investment in universal health coverage, they also levy criticism on industry for the lack of transparency and unreasonably high drug prices that compromise their ability to deliver optimal healthcare as punctuated by the WHO resolution on disclosure of drug prices [15].

Many of the aforementioned challenges (especially regulatory expertise and clinical capacity) have a disproportionate impact on rare disease drugs and patients, but there are additional barriers. Some are grounded in "high evidential uncertainty" in extending clinical trial data to real-world outcomes. This is highly problematic in countries that apply "traditional" health technology assessment (HTA) or valuebased assessment (VBA) methodology to RD therapies compared to those jurisdictions that use supplemental processes with greater flexibilities that treat RD treatments differently [16].

How could this list of RD medicines be used? A potential pathway is one based on EMA's EUMedicines4all (EUM4all) procedure. EMA established EUM4all to provide expert reviews on benefits and risks of medicines that would be used outside the EU, with emphasis on LMICs [17]. Subsequent analysis found that 138 regulatory approvals had been granted in 90 different countries worldwide for six medicines based on EUM4all opinions, with acknowledged great public health impact.

The EUM4all initiative dealt with a broad range of medicines with high impact in LMICs, but we propose that the procedure could profitably be applied to RD medicines. This paper is intended to elicit suggestions and call for collaborations on how to modify, disseminate, and use the list of medicines in the Table 1. Specifically, the RDTAWG seeks input from RD advocacy groups, healthcare providers, 
pharmaceutical companies, and government agencies. Subsequent actions include a conference to bring together key stakeholders to elaborate on the list, identify barriers and opportunities for application and collaborate on next steps. The ultimate goal is to enhance access to appropriate medicines for all rare disease patients throughout the world.

\section{Conclusions}

The limited number of approved therapeutic options, combined with the unavailability of existing treatments, significantly impair the life of rare disease patients in LMICs. While many countries have recently developed policies and regulations for rare diseases and orphan drugs, access to treatment remains variable among LMICs. With the vision of leaving no one behind, the IRDiRC RDTAWG used the FDA, EMA databases and China's Rare Diseases Catalog to extract approved drugs with orphan designations and create the first list of 215 essential medicinal products for rare diseases. The list was organized into seven disease categories, excluding rare cancers and rare infectious diseases. The ultimate goal of this list is to further stimulate interactions among patient organizations, health care providers, industry and government agencies to improve standards of care for rare diseases by promoting access to treatments.

\section{Declarations}

Funding: The IRDiRC Scientific Secretariat is funded by the European Union through the European Joint Programme on Rare Disease under the European Union's Horizon 2020 research and innovation programme Grant Agreement $N^{\circ} 825575$. The Scientific Secretariat is hosted at the French Institute of Health and Medical Research (INSERM) in Paris, France.

This work was supported in part by the Intramural Research Program of the National Human Genome Research Institute.

Disclaimer: The findings and recommendations in this article are those of the contributors, who participated based on their individual expertise and are responsible for the contents, and do not necessarily represent the views of the members of the International Rare Diseases Research Consortium (IRDiRC) nor any employers of the contributors.

Competing interests: The authors declare that the research was conducted in the absence of any commercial or financial relationships that could be construed as a potential conflict of interest.

Availability of data and materials: The datasets analysed as sources for the lists are available from the corresponding author upon request.

Ethics approval and consent to participate: The study does not involve human participants, human data or human tissue. No ethics approval and consent were required. 
Consent for publication: The study does not contain any individual person's data.

Authors Contribution: The RDTAWG was led by WG and DWR. WG extracted all the drugs with orphan designations and FDA approval, and initiated the redaction of the manuscript. SG revised the list of drugs extracted by WG. VH used the Orphanet and EMA databases to collate medicinal products for rare diseases that have European Community marketing authorizations. RY consulted China's Rare Diseases Catalog of 121 rare diseases to identify the drugs approved for the treatment of recognized rare conditions. WG, DWR, SG, VH, RY, GZ revised the list of medicinal products, edited the manuscript and validated its final version.

Acknowledgments: Core group members of the RDTAWG include WG, DWR, SG, SW, VH, RY, GZ. In addition, we would like to thank Rachel Bishop (National Eye Institute, NIH, USA), Marc Dooms (UZ Leuven, Belgium), Katharina Hohenfellner (RoMed Klinikum Rosenheim, Germany), Bela Melegh (University of Pecs, Hungary), Filippo Pinto e Vairo (Mayo Clinic, USA) and Manuel Posada (Instituto de Salud Carlos III, Spain) for their review of the list of essential medicinal products for rare diseases.

\section{Abbreviations}

IRDiRC: International Rare Diseases Research Consortium

RDTAWG: Rare Disease Treatment Access Working Group

RD: Rare Diseases

LMICs: Low-and-Middle-Income Countries

OMP: Orphan Medicinal Products

FDA: US Food and Drug Administration

EMA: European Medicines Agencies

WHO: World Health Organization

EU: European Union

HTA: Health Technology Assessment

VBA: Value Based Assessment

\section{References}

1. Search Orphan Drug Designations and Approvals [Internet]. U.S. FOOD \& DRUG Administration. [cited 2021 Jan 29]. Available from: https://www.accessdata.fda.gov/scripts/opdlisting/oopd/ 
2. Lists of medicinal products for rare diseases in Europe [Internet]. Orphanet; 2020. Available from: https://www.orpha.net/orphacom/cahiers/docs/GB/list_of_orphan_drugs_in_europe.pdf

3. Medicines Search [Internet]. European Medicines Agency. [cited 2021 Jan 29]. Available from: https://www.ema.europa.eu/en/medicines/ema_group_types/ema_orphan

4. China National Rare Disease Registry [Internet]. [cited 2021 Jan 29]. Available from: https://www.nrdrs.org.cn/app/rare/index.html

5. Drug Evaluation Center of the State Drug Administration [Internet]. [cited 2021 Jan 29]. Available from: http://www.cde.org.cn/

6. World Health Organization Model List of Essential Medicines - 21st List, 2019 [Internet]. World Health Organization. [cited 2021 Jan 29]. Available from: https://www.who.int/publications-detailredirect/WHOMVPEMPIAU2019.06

7. World Health Organization Model List of Essential Medicines for Children, 7th List, 2019 [Internet]. World Health Organization; 2019. Available from: https://apps.who.int/iris/bitstream/handle/10665/325772/WHO-MVP-EMP-IAU-2019.07-eng.pdf? sequence=1\&isAllowed=y

8. Gahl WA, Wise AL, Ashley EA. The Undiagnosed Diseases Network of the National Institutes of Health: A National Extension. JAMA. 2015;314:1797.

9. Chan AYL, Chan VKY, Olsson S, Fan M, Jit M, Gong M, et al. Access and Unmet Needs of Orphan Drugs in 194 Countries and 6 Areas: A Global Policy Review With Content Analysis. Value in Health. 2020;23:1580-91.

10. Gammie T, Lu CY, Babar ZU-D. Access to Orphan Drugs: A Comprehensive Review of Legislations, Regulations and Policies in 35 Countries. Garattini S, editor. PLoS ONE. 2015;10:e0140002.

11. Czech M, Baran-Kooiker A, Atikeler K, Demirtshyan M, Gaitova K, Holownia-Voloskova M, et al. A Review of Rare Disease Policies and Orphan Drug Reimbursement Systems in 12 Eurasian Countries. Front Public Health. 2020;7:416.

12. Stolk P. Rare essentials drugs for rare diseases as essential medicines. Bull World Health Organ. 2006;84:745-51.

13. Stevens H, Huys I. Innovative Approaches to Increase Access to Medicines in Developing Countries. Front Med. 2017;4:218.

14. Alsairi R. Access to Medicine in Developing Countries. American Journal of Medicine and Medical Sciences. 2017;7:271-6.

15. Fletcher ER. World Health Assembly Approves Milestone Resolution On Price Transparency [Internet]. Health Policy Watch; 2019 May. Available from: https://healthpolicy-watch.news/world-healthassembly-approves-milestone-resolution-on-price-transparency/

16. Nicod E, Whittal A, Drummond M, Facey K. Are supplemental appraisal/reimbursement processes needed for rare disease treatments? An international comparison of country approaches. Orphanet $\mathrm{J}$ Rare Dis. 2020;15:189. 
17. Cavaller Bellaubi M, Harvey Allchurch M, Lagalice C, Saint-Raymond A. The European Medicines Agency facilitates access to medicines in low- and middle-income countries. Expert Review of Clinical Pharmacology. 2020;13:321-5.

\section{Table}

Table 1 - Essential list of medicinal products for rare diseases (to be included after the Results section) 


\section{Aminoacid Disorders}

$\begin{array}{llc}\begin{array}{l}\text { Benzoate and } \\ \text { phenylacetate }\end{array} & \text { Hyperammonemia of urea cycle disorders } & \text { FDA } \\ \begin{array}{l}\text { Sodium } \\ \text { phenylbutyrate }\end{array} & \text { Urea cycle disorders } & \text { FDA, } \\ \text { Carglumic acid } & \text { EMA } & \text { FDA, } \\ & & \text { EMA } \\ \text { Betaine } & \text { Homocystinuria } & \text { FDA, } \\ & & \text { EMA } \\ \text { Sapropterin } & \text { Hyperphenylalaninemia, Tetrahydrobiopterin deficiency } & \text { FDA, } \\ & & \text { EMA, } \\ & & \text { China } \\ \text { Pegvaliase } & \text { Phenylketonuria } & \text { FDA, } \\ & & \text { EMA } \\ \text { Nitisinone } & \text { Tyrosinemia type } 1 & \text { FDA, } \\ & & \text { EMA }\end{array}$

\section{Lysosomal Storage Diseases}

\begin{tabular}{|c|c|}
\hline Miglustat & Gaucher disease \\
\hline Eliglustat & Gaucher disease type 1 \\
\hline Velaglucerase alfa & Gaucher disease type 1 \\
\hline Imiglucerase & Gaucher disease type 1 or Type 3 \\
\hline Taliglucerase & Gaucher disease \\
\hline Agalsidase beta & Fabry disease (alphagalactosidase A deficiency) \\
\hline Agalsidase alfa & Fabry disease (alphagalactosidase A deficiency) \\
\hline Migalastat & Fabry disease \\
\hline Sebelipase alfa & $\begin{array}{l}\text { Lysosomal acid lipase deficiency, Wolman disease, Cholesteryl } \\
\text { ester storage disease }\end{array}$ \\
\hline Alglucosidase alfa & Pompe disease \\
\hline Velmanase alfa & Alpha mannosidosis \\
\hline Laronidase & Mucopolysaccharidosis I (Iduronidase deficiency) \\
\hline Idursulfase & Hunter syndrome (Mucopolysaccharidosis II) \\
\hline Elosulfase alfa & Mucopolysaccharidosis IV (Morquio A syndrome) \\
\hline Galsulfase & Mucopolysaccharidosis VI (Maroteaux-Lamy syndrome) \\
\hline Vestronidase alfa & Mucopolysaccharidosis VII (Sly syndrome) \\
\hline Cerliponase alfa & Neuronal ceroid lipofuscinosis type 2 \\
\hline
\end{tabular}




\section{General}

\begin{tabular}{|c|c|}
\hline Inotersen & Hereditary transthyretin amyloidosis polyneuropathy \\
\hline Tafamidis & Transthyretin amyloidosis \\
\hline Patisiran sodium & Hereditary transthyretin amyloidosis \\
\hline Teriflunomide & Multiple Sclerosis \\
\hline Fingolimod $\mathrm{HCl}$ & Multiple Sclerosis \\
\hline Siponimod & Multiple Sclerosis \\
\hline Rasagiline & Parkinson Disease (Young and Early-onset) \\
\hline Selegiline & Parkinson Disease (Young and Early-onset) \\
\hline Pramipexole & Parkinson Disease (Young and Early-onset) \\
\hline Carbidopa/Levodopa & Parkinson Disease (Young and Early-onset); biopterin defects \\
\hline Pitolisant & Narcolepsy with or without cataplexy \\
\hline Sodium oxybate & Narcolepsy with cataplexy \\
\hline Deutetrabenazine & Huntington Disease \\
\hline Tetrabenazine & Huntington Disease \\
\hline Baclofen & Dystonia, Spasticity \\
\hline Capsaicin & Postherpetic neuralgia \\
\hline Naltrexone & Postherpetic neuralgia \\
\hline Ziconotide & Chronic pain requiring intrathecal analgesia \\
\hline Everolimus & Tuberous Sclerosis Complex \\
\hline Folic acid & Spina bifida (prevention) \\
\hline
\end{tabular}

\section{Epilepsy}

Vigabatrin Infantile spasms $\quad$ FDA

Rufinamide Lennox-Gastaut syndrome $\quad$ FDA

EMA

Cannabidiol Lennox-Gastaut syndrome and Dravet syndrome FDA,

EMA

Stiripentol Severe myoclonic epilepsy in infancy (Dravet syndrome) FDA,

$\begin{array}{lll}\text { Midazolam } & \text { EMA } \\ & \text { Status epilepticus } & \text { FDA }\end{array}$

Levetiracetam Juvenile myoclonic epilepsy, Generalized epilepsy EMA

Clobazam $\quad$ Complex and rare disease epilepsy $\quad$ FDA

$\begin{array}{lll}\text { Lamotrigine } & \text { Complex and rare disease epilepsy } & \text { FDA }\end{array}$

$\begin{array}{lll}\text { Topiramate } & \text { Complex and rare disease epilepsy } & \text { FDA }\end{array}$ 
Neuromuscular Diseases

$\begin{array}{llr}\text { Gabapentin } & \text { Amyotrophic lateral sclerosis } & \text { FDA } \\ \text { Riluzole } & \text { Amyotrophic lateral sclerosis } & \begin{array}{l}\text { FDA, } \\ \text { EMA, } \\ \text { China }\end{array} \\ \text { Radicava } & \text { Amyotrophic lateral sclerosis } & \text { China } \\ \text { Pyridostigmine } & \text { Myasthenia gravis } & \text { China } \\ \text { Bromide } & \text { Lambert-Eaton myasthenic syndrome } & \text { EMA } \\ \text { Amifampridine } & \text { Non-dystrophic myotonic disorders } & \text { EMA } \\ \text { Mexiletine hcl } & 5 q \text { Spinal Muscular Atrophy } & \text { FDA, } \\ \text { Nusinersen sodium } & & \text { EMA, } \\ & & \text { China }\end{array}$

\section{Coagulation Defects}

\begin{tabular}{|c|c|c|}
\hline Octocog alpha & Hemophilia A (Factor VIII deficiency) & EMA \\
\hline $\begin{array}{l}\text { Rurioctocog alfa } \\
\text { pegol }\end{array}$ & Hemophilia A (Factor VIII deficiency) & EMA \\
\hline Lonoctocog alfa & Hemophilia A (Factor VIII deficiency) & EMA \\
\hline Emicizumab & Hemophilia A (Factor VIII deficiency) & $\begin{array}{l}\text { FDA, } \\
\text { EMA, } \\
\text { China }\end{array}$ \\
\hline $\begin{array}{l}\text { Damoctocog alfa } \\
\text { pegol }\end{array}$ & Hemophilia A (Factor VIII deficiency) & EMA \\
\hline Turoctocog alpha & Hemophilia A (Factor VIII deficiency) & EMA \\
\hline Simoctocog alfa & Hemophilia A (Factor VIII deficiency) & EMA \\
\hline Moroctocog alpha & Hemophilia A (Factor VIII deficiency) & EMA \\
\hline $\begin{array}{l}\text { Desmopressin } \\
\text { acetate }\end{array}$ & Hemophilia & $\begin{array}{l}\text { FDA, } \\
\text { EMA }\end{array}$ \\
\hline $\begin{array}{l}\text { Recombinant Factor } \\
\text { VIII }\end{array}$ & Hemophilia A (Factor VIII deficiency) & $\begin{array}{l}\text { EMA, } \\
\text { China }\end{array}$ \\
\hline Efmoroctocog alfa & Hemophilia A (Factor VIII deficiency) & EMA \\
\hline $\begin{array}{l}\text { Factor VIII/ von } \\
\text { Willebrand factor }\end{array}$ & von Willebrand disease, Hemophilia A & EMA \\
\hline Vonicog alfa & von Willebrand disease & EMA \\
\hline Eftrenonacog alfa & Hemophilia B & EMA \\
\hline $\begin{array}{l}\text { Albutrepenonacog } \\
\text { alfa }\end{array}$ & Hemophilia B & EMA \\
\hline Nonacog alpha & Hemophilia B (Factor IX deficiency) & EMA \\
\hline $\begin{array}{l}\text { Human coagulation } \\
\text { factor IX }\end{array}$ & Hemophilia B (Factor IX deficiency) & EMA \\
\hline Nonacog beta pegol & Hemophilia B (Factor IX deficiency) & EMA \\
\hline Nonacog gamma & Hemophilia B (Factor IX deficiency) & EMA \\
\hline $\begin{array}{l}\text { Recombinant Factor } \\
\text { IX }\end{array}$ & Hemophilia B (Factor IX deficiency) & $\begin{array}{l}\text { EMA, } \\
\text { China }\end{array}$ \\
\hline $\begin{array}{l}\text { Eptacog alpha } \\
\text { (activated) }\end{array}$ & Hemophilia (Factor VII deficiency) & EMA \\
\hline $\begin{array}{l}\text { Recombinant Factor } \\
\text { VIIa }\end{array}$ & Hemophilia (Factor VII deficiency) & EMA \\
\hline
\end{tabular}




\begin{tabular}{llr}
$\begin{array}{l}\text { Human coagulation } \\
\text { factor X }\end{array}$ & Factor X deficiency & EMA \\
Catridecacog & Factor XIII A-subunit deficiency & EMA \\
\hline Human protein c & Protein C deficiency & EMA \\
& & FDA \\
& Anemias & FDA \\
\hline Hydroxyurea & Sickle cell anemia & FDA, \\
\hline Epoetin alfa & Anemia of end-stage renal disease & EMA \\
Eltrombopag & Idiopathic thrombocytopenic purpura, Aplastic anemia & FDA, \\
& & EMA, \\
Deferasirox & Beta thalassemia major & China
\end{tabular}

\section{Other Hematologic Disorders}

\begin{tabular}{|c|c|c|}
\hline $\begin{array}{l}\text { Methylene blue } \\
\text { injection }\end{array}$ & Congenital and acquired methemoglobinemia & FDA \\
\hline Hemin & Acute intermittent porphyria & FDA \\
\hline Afamelanotide & Erythropoietic protoporphyria & $\begin{array}{l}\text { FDA, } \\
\text { EMA }\end{array}$ \\
\hline Siltuximab & Multicentric Castleman's disease & $\begin{array}{l}\text { FDA, } \\
\text { EMA }\end{array}$ \\
\hline $\begin{array}{l}\text { Anagrelide } \\
\text { hydrochloride }\end{array}$ & Essential thrombocythemia & $\begin{array}{l}\text { FDA, } \\
\text { EMA }\end{array}$ \\
\hline Ravulizumab & Paroxysmal nocturnal hemoglobinuria & $\begin{array}{l}\text { FDA, } \\
\text { EMA }\end{array}$ \\
\hline Macapegfilgrastim & Severe congenital neutropenia & China \\
\hline Busulfan & Conditioning for hematopoietic stem cell transplant & $\begin{array}{l}\text { FDA, } \\
\text { EMA }\end{array}$ \\
\hline Thiotepa & Conditioning for hematopoietic stem cell transplant & $\begin{array}{l}\text { FDA, } \\
\text { EMA }\end{array}$ \\
\hline Deferiprone & Iron overload & $\begin{array}{l}\text { FDA, } \\
\text { EMA }\end{array}$ \\
\hline Caplacizumab & Acquired thrombotic thrombocytopenic purpura & $\begin{array}{l}\text { FDA, } \\
\text { EMA }\end{array}$ \\
\hline Romiplostim & Immune (idiopathic) thrombocytopenic purpura & $\begin{array}{l}\text { FDA, } \\
\text { EMA }\end{array}$ \\
\hline $\begin{array}{l}\text { Ropeginterferon } \\
\text { alfa- } 2 \mathrm{~b}\end{array}$ & Polycythemia vera & EMA \\
\hline Ruxolitinib & Polycythemia vera & $\begin{array}{l}\text { FDA, } \\
\text { EMA }\end{array}$ \\
\hline $\begin{array}{l}\text { Immunoglobulin } \\
\text { infusion }\end{array}$ & Agammaglobulinemia & China \\
\hline
\end{tabular}

\section{Anti-inflammatory}

\section{Rheumatoid Arthritis}

\begin{tabular}{llc} 
Methotrexate & Juvenile rheumatoid arthritis & FDA, \\
Etanercept & Juvenile rheumatoid arthritis & FDA, \\
& & EMA \\
Methylprednisolone & Juvenile rheumatoid arthritis & EMA \\
\hline Adalimumab & Juvenile rheumatoid arthritis, Pediatric ulcerative colitis & FDA \\
Infliximab & Crohn's disease, Juvenile rheumatoid arthritis, Sarcoidosis & FDA
\end{tabular}




\section{Gastrointestinal Inflammation}

$\begin{array}{lll}\begin{array}{l}\text { Mesalamine; } 5- \\ \text { aminosalicylic acid }\end{array} & \text { Ulcerative colitis } & \text { FDA } \\ \text { Obeticholic acid } & \text { Primary biliary cholangitis } & \text { FDA, } \\ & & \text { EMA } \\ \text { Tocofersolan } & \text { Hereditary chronic cholestasis } & \text { EMA }\end{array}$

\section{Angioedema}

C1 inhibitor(human) Hereditary angioedema $\quad$ EMA

Icatibant acetate Hereditary angioedema FDA,

EMA

Lanadelumab Hereditary angioedema FDA,

EMA,

China

Danazol

Hereditary angioedema

China

Tranexamic acid

Hereditary angioedema

FDA,

China

C1-esterase-

Angioedema due to C1 esterase inhibitor deficiency

FDA

inhibitor, human

Conestat alfa

\section{Other Inflammatory Disorders}

\section{Colchicine}

Eculizumab

Rituximab

Canakinumab

IL-1 Receptor antagonist anakinra

Cenegermin

Ciclosporin

Dexamethasone

Rilonacept
Multiple sclerosis, Behcet's disease, Familial Mediterranean fever

Dermatomyositis, Atypical hemolytic uremic syndrome,

Neuromyelitis Optica, Paroxysmal nocturnal hemoglobinuria, Myasthenia gravis

Anti-neutrophil vasculitis, Wegener's granulomatosis, ChurgStrauss Syndrome

Familial Mediterranean fever, Cryopyrin fevers

Still's disease, Systemic juvenile arthritis

Neurotrophic keratitis

Vernal keratoconjunctivitis

Non-infectious uveitis

Cryopyrin-associated periodic syndromes
FDA,

China

FDA,

EMA,

China

FDA

FDA,

EMA,

China

FDA,

EMA

FDA, EMA EMA

FDA, EMA FDA, EMA

\section{Endocrine}

Somatropin for injection

Octreotide

Lanreotide
Growth hormone deficiency in children

FDA, EMA FDA Acromegaly Acromegaly 


\begin{tabular}{lll} 
Pegvisomant & Acromegaly & FDA, \\
& & EMA \\
Pasireotide & Acromegaly and Cushing's syndrome & FDA, \\
& & EMA \\
Osilodrostat & Endogenous Cushing's syndrome & EMA \\
& & EMA \\
Ketoconazole & Endogenous Cushing's syndrome & FDA, \\
Hydrocortisone & Adrenal insufficiency & EMA, \\
& & China \\
Human chorionic & Idiopathic Hypogonadotropic Hypogonadism & China \\
gonadotropin & & EMA, \\
Gonadotropin- & Idiopathic Hypogonadotropic Hypogonadism & China \\
releasing hormone & & FDA, \\
Mecasermin & Primary insulin-like growth factor-1 deficiency & EMA \\
& & FDA \\
Calcitonin-human & Paget's disease (osteitis deformans) & \\
for injection & & FDA, \\
Parathyroid & Hypoparathyroidism & EMA \\
hormone & & FDA, \\
\hline Tasimelteon & Non-24-hour sleep-wake disorder & EMA \\
& & FDA, \\
\hline Metreleptin & Leptin deficiency in lipodystrophy patients & EMA \\
& & EMA
\end{tabular}

Pulmonary

\section{Pulmonary Arterial Hypertension}

Macitentan Pulmonary arterial hypertension

FDA,

EMA,

China

Tadalafil

Pulmonary arterial hypertension

FDA,

EMA

Ambrisentan

Pulmonary arterial hypertension

FDA,

EMA,

China

Nitric oxide

Pulmonary arterial hypertension

FDA,

EMA

Sildenafil

Pulmonary arterial hypertension

EMA,

China

Bosentan

Pulmonary arterial hypertension, systemic sclerosis

FDA,

monohydrate

EMA,

China

Selexipag

Pulmonary arterial hypertension

FDA,

EMA,

China

Iloprost

Pulmonary arterial hypertension

FDA,

EMA,

China

Parenteral

Pulmonary arterial hypertension

FDA,

treprostinil

EMA,

China

Riociguat

Thromboembolic pulmonary hypertension and Pulmonary

FDA,

arterial hypertension

EMA,

China

Cystic Fibrosis

Page 16/18 


$\begin{array}{llc}\text { Mannitol } & \text { Cystic fibrosis } & \text { FDA, } \\ & & \text { EMA } \\ \text { Ivacaftor } & \text { Cystic fibrosis } & \text { FDA, } \\ & & \text { EMA } \\ \text { Tezacaftor/ivacaftor } & \text { Cystic fibrosis } & \text { FDA, } \\ & & \text { EMA } \\ \text { Tobramycin } & \text { Cystic fibrosis } & \text { FDA, } \\ \text { Aztreonam } & \text { Cystic fibrosis } & \text { FMA } \\ & & \text { FMA } \\ \text { Colistimethate } & \text { Cystic fibrosis } & \text { EMA } \\ \text { sodium } & & \\ \text { Lumacaftor } / & \text { Cystic fibrosis } & \text { FDA, } \\ \text { ivacaftor } & & \text { EMA } \\ \text { Levofloxacin } & \text { Cystic fibrosis } & \text { EMA }\end{array}$

\section{Other Pulmonary Disorders}

Pirfenidone $\quad$ Idiopathic Pulmonary Fibrosis $\quad$ FDA

EMA

Nintedanib Idiopathic Pulmonary Fibrosis $\quad$ FDA,

EMA,

China

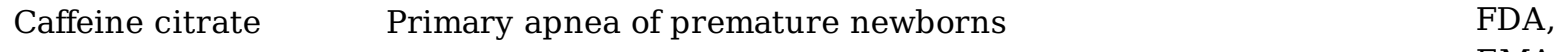

EMA

\section{Immunologic}

$\begin{array}{llr}\text { Pegademase bovine } & \text { Enzyme replacement for Adenosine deaminase deficiency (ADA) } & \text { FDA } \\ \begin{array}{lll}\text { CD34+ cells } \\ \text { transduced with }\end{array} & \begin{array}{l}\text { Severe combined immunodeficiency, Adenosine deaminase } \\ \text { deficiency (ADA) }\end{array} & \text { EMA } \\ \begin{array}{ll}\text { ADA cDNA } \\ \text { b }\end{array} & \text { FDA } & \text { FDA } \\ \text { Tacrolimus } & \text { Prophylaxis of graft-versus-host-disease, Graft rejection } & \text { FDA, } \\ \text { Sirolimus } & \text { Lymphangioleiomyomatosis, Tuberous sclerosis } & \text { EMA }\end{array}$

Miscellaneous

Pentamidine

Pneumocystis carinii pneumonia

FDA

isethionate

Cromolyn sodium

Mastocytosis

FDA

Amiodarone

Ventricular tachycardia

FDA

Autologous human

Limbal stem cell deficiency

EMA

corneal stem cells

Inherited retinal dystrophy $\quad$ FDA,

Voretigene

EMA

Teduglutide

Short bowel syndrome

FDA,

EMA

Defibrotide

Hepatic veno-occlusive disease, Sinusoidal obstruction

FDA,

EMA

Proteolytic enzymes

Deep partial- and full-thickness thermal burns

EMA

with bromelain

Tolvaptan

Autosomal dominant polycystic kidney disease

FDA,

Ibuprofen

Patent ductus arteriosus

EMA

FDA,

EMA

Page 17/18 
Table 1: List of 215 essential medicinal products with orphan designation extracted from the FDA database and/or EMA database and/or Chinas's Rare Diseases Catalog. 